\title{
Effect of water soaking pretreatment on the quality of glutinous rice cookies
}

\author{
Hun-Sik Chung ${ }^{1}$, Han-Sol Park ${ }^{1}$, Hyeon-Jeong Lee ${ }^{2}$, Jin-Ho Woo ${ }^{2}$, \\ Kwang-Deog Moon ${ }^{2}$, Kwang-Sup Youn ${ }^{3 *}$ \\ ${ }^{1}$ Department of Food Science and Technology, Pusan National University, Miryang 50463, Korea \\ ${ }^{2}$ School of Food Science and Biotechnology, Kyungpook National University, Daegu 41566, Korea \\ ${ }^{3}$ Department of Food Science and Technology, Daegu Catholic University, Gyeongsan 38430, Korea
}

\begin{abstract}
In this study, we aimed to improve the quality of rice cookies by investigating the preparation of the principal ingredient, glutinous rice (Oryza sativa var. glutinosa 'Dongjin'). The effects of pre-milling water soaking on the quality characteristics of the rice flour and resultant rice cookies were investigated; in particular, the characteristics of cookies made from water-soaked and untreated rice flours were compared. Rice flour, sugar, butter, salt, egg, and baking powder were mixed together to from a dough, which was then cut (thickness $3 \mathrm{~mm}$ and diameter $35 \mathrm{~mm}$ ), baked for $9 \mathrm{~min}$ at $170-180^{\circ} \mathrm{C}$, cooled, and packaged in plastic bags. In glutinous rice cookies prepared from water-soaked rice flour, the moisture content, water activity, and hue and red-green $\left(h^{\circ}\right.$ and $\left.-\mathrm{a}^{*}\right)$ color values were significantly higher but the yield, spread ratio, bulk density, hardness, lightness, yellow-blue and chroma $\left(L^{*}\right.$, $b^{*}$ and $C^{*}$ ) color values, phenolic compound contents, and 2,2-diphenyl-1-picrylhydrazyl (DPPH) activity were significantly lower than those prepared from untreated rice flour. These results suggest that the treatment of glutinous rice grain by water soaking before milling affects the quality properties of the resultant cookies, and the pretreatment of glutinous rice results in cookies with a darker color, softer texture, and lower antioxidant ability.
\end{abstract}

Key words : Oryza sativa, cookies, water soaking, glutinous rice, gluten free

\section{Introduction}

Rice can be divided into Asian species (Oryza sativa L.) and African species (Oryza glaberrima Steud), and the Asian species can be further subdivided into japonica, indica, and glutinous rice according to the shape of grain and the amylose and amylopectin content of the rice starch (1). Glutinous rice contains starch molecules that consist of approximately $0.8-1.3 \%$ amylose (2), and this rice is easier to digest and its starch retrogradation is slower than that of japonica rice (3). Rice is not only a valuable source of macro- and micronutrients, but also contains functional ingredients, including tocopherol, tocotrienole, $\gamma$-oryzanol, ferulic acid,

*Corresponding author. E-mail : ksyoun@cu.ac.kr

Phone : 82-53-850-3209, Fax : 82-53-850-3209

Received 03 January 2019; Revised 29 January 2019; Accepted 31 January 2019.

Copyright (c) The Korean Society of Food Preservation. All rights reserved. p-coumaric acid, benzoic acid, $\beta$-sitosterol, stigmasterol, squalene, and octacosanol (4).

In Korea, glutinous rice has traditionally been consumed as rice cakes, sweet rice drinks, and rice wine (5). However, rice consumption, including that of glutinous rice, is decreasing but production is not decreasing accordingly; thus, studies are needed to identify ways to stabilize supply and demand and increase the food self-sufficiency rate in Korea (5). Consequently, research on high quality rice and highvalue-added products prepared using rice has been conducted. Furthermore, recently, interest in the manufacture of various processed products using rice flour has increased. There are two types of rice flour that differ by the use of water soaking before milling; these are termed as a dry-milled and a wet-milled flour (6). Soaking rice in excess water before cooking is a traditional practice that reduces the cooking time and energy consumption and changes the quality characteristics of the products prepared from the rice $(7,8)$. However, the effects of the water soaking treatment on the 
quality characteristics of cookies prepared from glutinous rice flour have not been reported.

Cookies are small, flat, sweet baked foods made from wheat flour, sugar, and fat as the main ingredients. Wheat flour contains gluten, a known allergen, and, thus, numerous studies have been conducted to replace wheat flour with gluten-free rice flour (9). Microwave irradiation (10), extrusion (11), emulsification (12), and enzyme (13) treatments have been applied to modify rice flour for cookie manufacture, and it has been found that these treatments significantly change the quality of the resultant rice cookies. The effects of the addition of Kalopanax pictus leaves (14), Ligularia fischeri leaves (15), Sesamum indicum (sesame) (16), roasted soybean (Glycine max) (17), Lentinus edodes (shiitake) (18), and Smallanthus sonchifolius tubers (yacon) (19) on the quality characteristics of rice cookies have been studied by numerous researchers. It has also been reported that rice varieties containing higher amylose content among japonica rice are better suited for cookie preparation $(20,21)$. We assume that japonica rice and glutinous rice differ in their suitability for cookie manufacturing and that the water-soaking pretreatment may affect the production of rice flour. However, the effects of water soaking pretreatments on quality of cookies prepared from glutinous rice have not been reported previously.

Therefore, we aimed to evaluate the quality characteristics of the rice cookies prepared from glutinous rice flours as well as the effects of water-soaking treatment before the milling of rice grain into flour, on the quality of the cookies.

\section{Materials and methods}

\section{Materials}

Glutinous rice (Oryza sativa var. glutinosa 'Dongjin') was purchased from a local market in the Sangju region of Korea. Cookie ingredients such as sugar (CJ Cheiljedang Co., Incheon, Korea), butter (Seoul milk Co., Yongin, Korea), salt (Hanju Co., Ulsan, Korea), egg (Haemil Farming Association Co., Yeoju, Korea), and baking powder (Jeonwon Food, Gimpo, Korea) were purchased from a food market. Folin-Ciocalteu reagent was from Junsei Chemical Co. (Tokyo, Japan), and gallic acid and 2,2-diphenyl-1picrylhydrazyl (DPPH) were obtained from Sigma-Aldrich Chemical Co. (St. Louis, MO, USA). All other chemicals used for analysis were of high purity.

\section{Preparation of rice cookies}

Rice was soaked in water for $12 \mathrm{~h}$ at $20^{\circ} \mathrm{C}$, milled, and then sieved (40 mesh). The water-soaked glutinous rice flour and untreated glutinous rice flour (control) were used for cookie preparation. The cookie formulation was rice flour (200 g), sugar (40 g), butter (50 g), salt (0.8 g), baking powder $(1 \mathrm{~g})$, and egg (40 g). The formulation used in the cookie preparation was standardized on the basis of the preliminary tests. The egg, butter, and sugar were creamed in a hand mixer equipped with a wire whip beater set. Rice flour and baking powder were mixed with the creamed ingredients. The dough was aged in a refrigerator at $10^{\circ} \mathrm{C}$ for $30 \mathrm{~min}$, sheeted to a thickness of $3 \mathrm{~mm}$ using a rolling pin and cut with a cookie cutter of $35 \mathrm{~mm}$ diameter. The rounded cookie dough was transferred to a baking tray and baked in a pre-heated oven (FDO-7102, Daeyoung Bakery Machinery Ind., Co., Seoul, Korea) at an upper temperature of $180^{\circ} \mathrm{C}$ and lower temperature of $170^{\circ} \mathrm{C}$ for $9 \mathrm{~min}$. The baked cookies were allowed to cool to $25^{\circ} \mathrm{C}$ for $1 \mathrm{~h}$, and packaged in a nylon/polyethylene bags of 0.08-mm thickness, and kept until further quality analysis.

Measurements of cookie yield, spread ratio, and bulk density

The cookie yield was estimated from the difference between the weight of cookies before and after baking. The thickness and diameter were measured with a digital Vernier caliper (CD-20APX, Mitutoyo Co., Kanagawa, Japan). The spread ratio was expressed as diameter $(\mathrm{mm}) /$ thickness $(\mathrm{mm})$. The bulk density was determined by measuring the volume of a known mass of cookies and is expressed as the weight $(\mathrm{kg})$ to volume $\left(\mathrm{m}^{3}\right)$ ratio. The volume of the cookie was determined by the rape-seed displacement method.

\section{Measurements of moisture and water activity}

The moisture content of the rice cookies was determined by drying at $105^{\circ} \mathrm{C}$ until insignificant consecutive weight changes were measured. The water activity of the rice cookies was determined at $25^{\circ} \mathrm{C}$ using a water activity meter (Thermoconstanter, TH200, Novasina, Lachen, Switzerland).

\section{Measurement of hardness}

The hardness of ten cookies from each batch was measured using a rheometer (Compac-100II, Sun Scientific Co., Tokyo, Japan) equipped with a $3 \mathrm{~mm}$ diameter probe. The penetration depth and table speed were $2 \mathrm{~mm}$ and $120 \mathrm{~mm} / \mathrm{min}$, respectively. The individual samples of cookies were placed 
on the platform and the probe penetrated the center of sample. The maximum peak force was considered as the hardness of the cookies and is expressed in Newton units $(\mathrm{N})$.

\section{Color measurement}

The color properties of the top and the bottom surfaces of ten cookies sampled for each batch were measured using a colorimeter (CR-400, Konika Minolta Inc., Tokyo, Japan) fitted with a CIE illuminant $\mathrm{C}$ and 8-mm diameter measuring aperture, which was calibrated with a standard white plate $\left(L^{*}=97.79, a^{*}=-0.38, b^{*}=2.05\right)$, and are expressed as the mean of two measured values for each cookie. The $L^{*}$ value represents the lightness, whereas $-a^{*}$ and $b^{*}$ values represent greenness and yellowness, respectively. The $h^{\circ}$ value represents the color tone (hue), and is defined as red-purple: $0^{\circ}$, yellow: $90^{\circ}$, bluish-green: $180^{\circ}$, and blue: $270^{\circ}$, and was calculated as $h^{\circ}=\tan ^{-1}\left(b^{\star} / a^{*}\right)$. The $C^{\star}$ value is a measurement of color purity or saturation and was calculated as $\left(\mathrm{a}^{\star 2}+\mathrm{b}^{\star 2}\right)^{1 / 2}$.

\section{Measurement of phenolic compounds}

The phenolic compound content was measured according to the Folin-Ciocalteu procedure (22). Five grams of cookie samples were mixed with 10 volumes of $80 \%$ ethanol and homogenized using a homogenizer (T25 Basic, IKA, Staufen, Germany). The homogenate was extracted at $20^{\circ} \mathrm{C}$ for 24 h, filtered through a filter paper (No. 2, Advantec, Tokyo, Japan), and the filtrate was used for analysis. A portion (2 $\mathrm{mL}$ ) of the extracts was then transferred into a test tube. Then, Folin-Ciocalteu reagent $(2 \mathrm{~mL})$ was added and mixed thoroughly. After $5 \mathrm{~min}, 2 \mathrm{~mL}$ of $10 \% \mathrm{Na}_{2} \mathrm{CO}_{3}$ solution was added and the mixture was incubated for $1 \mathrm{~h}$. The absorbance of the resulting solution was measured using a spectrophotometer (UV1800, Shimadzu, Kyoto, Japan) at 760 $\mathrm{nm}$. The contents of soluble tannins was measured by comparison with the absorbance values of different concentrations of the gallic acid standard.

\section{Measurement of DPPH radical scavenging activity}

The radical scavenging activity was determined using the DPPH radical scavenging assay (23). Five grams of cookie was mixed with 10 volumes of $80 \%$ ethanol and homogenized using a homogenizer (T25 Basic, IKA). The homogenate was extracted at $20^{\circ} \mathrm{C}$ for $24 \mathrm{~h}$, filtered through filter paper (No. 2, Advantec), and the filtrate was used as extract samples for the analysis. The extracts $(0.2 \mathrm{~mL})$ were added to 0.8 $\mathrm{mL}$ of a $0.4 \mathrm{mmol} / \mathrm{L} \mathrm{DPPH}$ radical solution in ethanol. The mixture was vigorously shaken and incubated for $10 \mathrm{~min}$. The absorbance of the resulting solution was measured at
$525 \mathrm{~nm}$ using a spectrophotometer (UV1800, Shimadzu). The radical scavenging activity was calculated using the following formula: DPPH radical scavenging activity $(\%)=[1-($ absorbance of sample/absorbance of DPPH)] $\times 100$.

\section{Statistical analysis}

All experiments were performed at least in triplicate, and the data are presented as the mean \pm standard deviation (SD). The effects of the water soaking pretreatment on the quality characteristics of the rice cookies were assessed using the analysis of variance (ANOVA), and the mean values were compared using t-test $(\mathrm{p}<0.05)$. All statistical analyses were performed using an IBM SPSS statistics software (20; IBM Corp., Armonk, NY, USA).

\section{Results and discussion}

Comparison of cookie yield, spread ratio, and bulk density

The cookie yields, spread ratios, and bulk densities of the cookies prepared from water-soaked glutinous rice flour are listed in Table 1. The cookie yield, spread ratio, and bulk density of cookies were significantly affected $(\mathrm{p}<0.05)$ by the water soaking pretreatment. The cookie yield is generally considered a measure of weight loss as a result of baking. The cookie yield was significantly higher in the cookies prepared from the control flour than those prepared from water-soaked rice flour (Table 1). This result may be explained by the large loss of moisture from the high initial moisture content arising from the water soaking pretreatment (12).

The spread ratio is a measure of the thickness reduction and diameter increase of the dough on baking, which is known to be determined by the raw material characteristics and the dough and baking conditions, and higher hardness, indicates higher quality $(13,14,18,21)$. The spread ratio was higher in cookies prepared from the control than from water-soaked rice flour (Table 1), possibly because of the differences in the viscosity of the dough (20). This result indicates that the water soaking before milling affected the spread ratio of the cookies prepared from glutinous rice.

The bulk density indicates the degree of expansion of dough caused by baking, and an increase in this value is a physical property associated with the cookie texture, indicating that expansion is suppressed $(13,14)$. The bulk density was lower in the cookies prepared from the water-soaked rice flour than 
those prepared from the control rice (Table 1). This result may be due to the porous structure resulting from the significant water evaporation on baking in the cookies prepared from water-soaked glutinous rice flour (17).

Table 1. Effects of water soaking pretreatment on yield, spread ratio, and bulk density of cookies prepared from glutinous rice

\begin{tabular}{ccc}
\hline \multirow{2}{*}{ Quality characteristics } & \multicolumn{2}{c}{ Glutinous rice } \\
\cline { 2 - 3 } & Control & Water-soaked \\
\hline Cookie yield (weight/weight) & $0.86 \pm 0.11^{1)}$ & $0.72 \pm 0.04^{* 2}$ \\
Spread ratio (diameter/thickness) & $5.80 \pm 0.12$ & $5.12 \pm 0.18^{*}$ \\
Bulk density $\left(\mathrm{kg} / \mathrm{m}^{3}\right)$ & $878 \pm 110$ & $516 \pm 87^{*}$ \\
\hline
\end{tabular}

${ }^{1)}$ Values represent the mean \pm standard deviation $(\mathrm{n}=3)$.

${ }^{2}$ Significant at $p<0.05$.

Comparison of moisture content, water activity, and hardness

The moisture content and water activity of cookies prepared from water-soaked or control rice flour are presented in Table 2 . The moisture content and water activity of the cookies were significantly affected $(\mathrm{p}<0.05)$ by the water soaking treatments before milling the rice grain. The moisture content and water activity of food materials are generally used as a measure of quality and storage stability. The moisture content was significantly higher in cookies prepared from the water-soaked rice than those prepared from the control.

The water activity was higher in cookies prepared from water-soaked rice flour than in cookies prepared from the control (Table 2). The effect of water soaking on the water activity of the cookies is similar to that of the moisture content of the cookies. These results suggest that the water soaking treatment of rice grain before milling has a negative effect on the quality stability of cookies.

The hardness values of the cookies prepared from water soaked rice flour or control are presented in Table 2. The cookie hardness was significantly affected $(\mathrm{p}<0.05)$ by soaking the rice in water before milling. The hardness was found to be eight times higher in the cookies prepared from the control than that of cookies prepared from the water-soaked glutinous rice (Table 2). The effect of the water soaking pretreatment on the hardness of cookies was the reverse of those of the moisture content and water activity. It is well known that the hardness of cookies is closely related to the moisture content $(13,15)$. The above results indicate that soaking rice in water before milling has an undesirable effect on the hardness of cookies.
Table 2. Effects of water soaking pretreatment on moisture content, water activity, and hardness of cookies prepared from glutinous rice

\begin{tabular}{ccc}
\hline \multirow{2}{*}{ Quality characteristics } & \multicolumn{2}{c}{ Glutinous rice } \\
\cline { 2 - 3 } & Control & Water-soaked \\
\hline Moisture content $(\%)$ & $8.33 \pm 0.83^{1)}$ & $10.01 \pm 1.05^{\star 2}$ \\
Water activity & $0.63 \pm 0.02$ & $0.78 \pm 0.01^{*}$ \\
Hardness $(\mathrm{N})$ & $33.83 \pm 7.42$ & $4.24 \pm 2.60^{*}$ \\
\hline
\end{tabular}

${ }^{1)}$ Values represent the mean \pm standard deviation $(\mathrm{n}=3)$

${ }^{2)}$ Significant at $\mathrm{p}<0.05$.

\section{Comparison of color values}

The color values $\left(\mathrm{L}^{*}, \mathrm{a}^{*}, \mathrm{~b}^{*}, \mathrm{C}^{*}\right.$, and $\left.\mathrm{h}^{\circ}\right)$ of the cookies prepared from glutinous rice flour (water soaked and control) are presented in Table 3. All color values of the rice cookies were significantly affected $(\mathrm{p}<0.05)$ by the water soaking pretreatment. The $L^{*}$ value was lower in the cookies prepared from water-soaked rice than that of those prepared from the control, whereas $-\mathrm{a}^{*}$ value was higher in the cookies prepared from water-soaked rice flour than those prepared from the control flour. The $b^{*}$ and $C^{*}$ values of the cookies prepared from water-soaked rice were lower than those that of the cookies prepared from the control. The $\mathrm{h}^{\circ}$ value of the cookies prepared with water-soaked flour was increased. The color of the cookies depends on non-enzymatic browning reactions $(13,15)$. The above results indicate that the water soaking pretreatment had the effect of lowering all color values, except for the $-\mathrm{a}^{*}$ and $\mathrm{h}^{\circ}$ values, of the glutinous rice cookies.

Table 3. Effects of water soaking pretreatment on color properties of cookies prepared from glutinous rice

\begin{tabular}{ccc}
\hline \multirow{2}{*}{ Color property } & \multicolumn{2}{c}{ Glutinous rice } \\
\cline { 2 - 3 } & Control & Water-soaked \\
\hline $\mathrm{L}^{*}$ value & $78.75 \pm 0.76^{1)}$ & $72.13 \pm 2.37^{* 2)}$ \\
$\mathrm{a}^{*}$ value & $-1.63 \pm 0.16$ & $-1.98 \pm 0.67^{*}$ \\
$\mathrm{~b}^{*}$ value & $26.91 \pm 0.62$ & $19.68 \pm 1.52^{*}$ \\
$\mathrm{C}^{*}$ value & $26.96 \pm 0.61$ & $19.79 \pm 1.49^{\star}$ \\
$\mathrm{h}^{\circ}$ value & $93.47 \pm 0.38$ & $95.83 \pm 2.13^{*}$ \\
\hline
\end{tabular}

${ }^{1)}$ Values represent the mean \pm standard deviation $(n=3)$.

${ }^{2)}$ Significant at $\mathrm{p}<0.05$.

\section{Comparison of phenolic compounds and DPPH activity}

The phenolic compound content and DPPH radical scavenging activity of cookies prepared from water-soaked glutinous rice flour and the control flour are presented in Fig. 1. Both properties of the rice cookies were significantly 
affected $(\mathrm{p}<0.05)$ by the water soaking pretreatment. The content of phenolic compounds was lower in the cookies prepared from water-soaked rice than from control. This result may be explained by the leaching of the phenolic compounds from the rice grain during water soaking and milling.

The DPPH radical scavenging activity was investigated to determine the antioxidant activity of the rice cookies. The DPPH radical scavenging activity was lower in the cookies prepared from water-soaked rice flour than from control. (Fig. 1). This may be related to antioxidant contents in cookies $(15,18)$. These results suggested that water soaking pretreatment contributes to lowering the phenolics contents and antioxidant activity of cookies.

In conclusion, the water soaking pretreatment affected the quality of the glutinous rice cookies. The increase in the moisture content, water activity, $-\mathrm{a}^{*}$ value, and $\mathrm{h}^{\circ}$ value of cookies and the decrease in the yield, spread ratio, bulk density, hardness, color values $\left(\mathrm{L}^{*}, \mathrm{~b}^{*}\right.$, and $\left.\mathrm{C}^{*}\right)$, phenolic compounds content, and DPPH activity of cookies were observed by application of water soaking pretreatment. The results of this study suggested that the water soaking pretreatment of glutinous rice darkens cookies, softens cookie texture, and reduces the antioxidant ability of cookies.

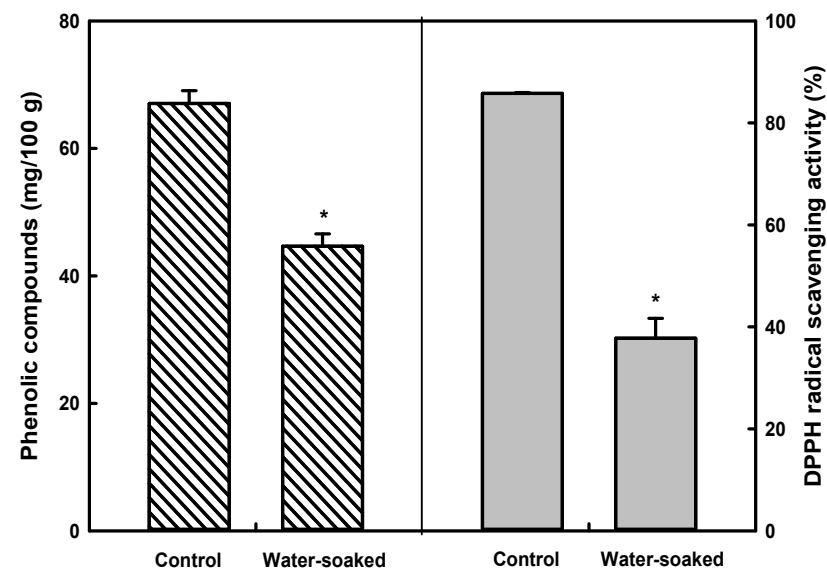

Fig. 1. Effects of water soaking pretreatment on phenolic compound content and DPPH radical scavenging activity of cookies prepared from glutinous rice.

Values represent the mean \pm standard deviation $(\mathrm{n}=3)$. * Significant at $\mathrm{p}<0.05$.

\section{Acknowledgment}

This research was supported by a grant from the Rural Development Administration (Project No. PJ011647)

\section{References}

1. Kim YG, Chun A (2010) Present status and prospect of rice cultivars for processing. Food Preserv Process Indus, 9, 3-12

2. Choi ID (2010) Physicochemical properties of rice cultivars with different amylose contents. J Korean Soc Food Sci Nutr, 39, 1313-1319

3. Jung EJ, Woo KJ (2006) Quality characteristics of Chalduk according to the soaking time of glutinous rice in water. J East Asian Soc Dietary Life, 16, 677-683

4. Ha TY (2008) Health functional properties of rice. Food Ind Nutr, 13, 22-26

5. Kim MR (2011) The status of Korea's rice industry and the rice processing industry. Food Ind Nutr, 16, 22-26

6. Han HM, Cho JH, Koh BK (2012) Effect of grinding method on flour quality in different rice cultivars. J Korean Soc Food Sci Nutr, 41, 1596-1602

7. Yu L, Turner MS, Fitzgerald M, Stokes JR, Witt T (2017) Review of the effects of different processing technologies on cooked and convenience rice quality. Trends Food Sci Technol, 59, 124-138

8. Kim K, Kang KJ, Lee YH, Kim SK (1993) Changes in properties of waxy rice during steeping in water. Korean J Food Sci Technol, 25, 86-87

9. Gallaghera E, Gormleya TR, Arendt EK (2004) Recent advances in the formulation of gluten-free cereal-based products. Trends Food Sci Technol, 15, 143-152

10. Villanueva M, Harasym J, Munoz JM, Ronda F (2018) Microwave absorption capacity of rice flour. Impact of the radiation on rice flour microstructure, thermal and viscometric properties. J Food Eng, 224, 156-164

11. We GJ, Lee IA, Kang TY, Min JH, Kang WS, Ko SH (2011) Physicochemical properties of extruded rice flours and a wheat flour substitute for cookie application. Food Eng Progress, 15, 404-412

12. Lee JK, Jeong JH, Lim JK (2012) Effects of emulsifiers on physical properties of rice cookies. J Korean Soc Food Sci Nutr, 41, 1565-1570

13. Kim MS, Park JD, Lee HY, Kum JS (2013) Effect of rice flour prepared with enzyme treatment on quality characteristics of rice cookies. J Korean Soc Food Sci Nutr, 42, 1439-1445

14. Lee EJ, Jin SY (2015) Antioxidant activity and quality characteristics of rice cookies added Kalopanax pictus leaf powder. J East Asian Soc Dietary Life, 25, 672-680 15. Joeng YJ, Han YS (2015) Antioxidative activities and 
quality characteristics of rice cookies with added Ligularia fischeri (Ledeb.) Turcz. powder. Korean J Food Cook Sci, 31, 733-740

16. Jung YJ, Seo HS, Myung JE, Shin JM, Lee EJ, Hwang IK (2007) Physicochemical and sensory characteristics of rice cookies based on Goami 2 with sesames (white and black) and perilla seeds. Korean J Food Cookery Sci, 23, 785-792

17. Lee JK, Lim JK (2013) Effects of roasted soybean flour on textural properties of rice cookies. J Korean Soc Food Sci Nutr, 42, 1426-1432

18. Kim MJ, Chung HJ (2017) Quality characteristics and antioxidant activities of rice cookies added with Lentinus edodes powder. Korean J Food Preserv, 24, 421-430

19. Lee JA (2014) Quality characteristics of rice cookies prepared with yacon (Smallanthus sonchifolius) powder. Korean J Culinary Res, 20, 100-112
20. Kwon YR, Jung MH, Cho JH, Song YC, Kang HW, Lee WY, Youn KS (2011) Quality characteristics of rice cookies prepared with different amylose contents. J Korean Soc Food Sci Nutr, 40, 832-838

21. Kang TY, Jo HE, Sohn KH, Youn MR, Lee JS, Lee SY, Ko SH (2016) Effect of rice variety on the processability for preparing rice cookies. Korean J Food Sci Technol, 48, 492-495

22. Singleton VL, Rossi JA (1965) Colorimetry of total phenolics with phosphomolybdic-phosphotungstic acid regents. Am J Enol Vitic, 16, 144-158

23. Blois MS (1958) Antioxidant determination by the use of a stable free radical. Nature, 181, 1199-1200 